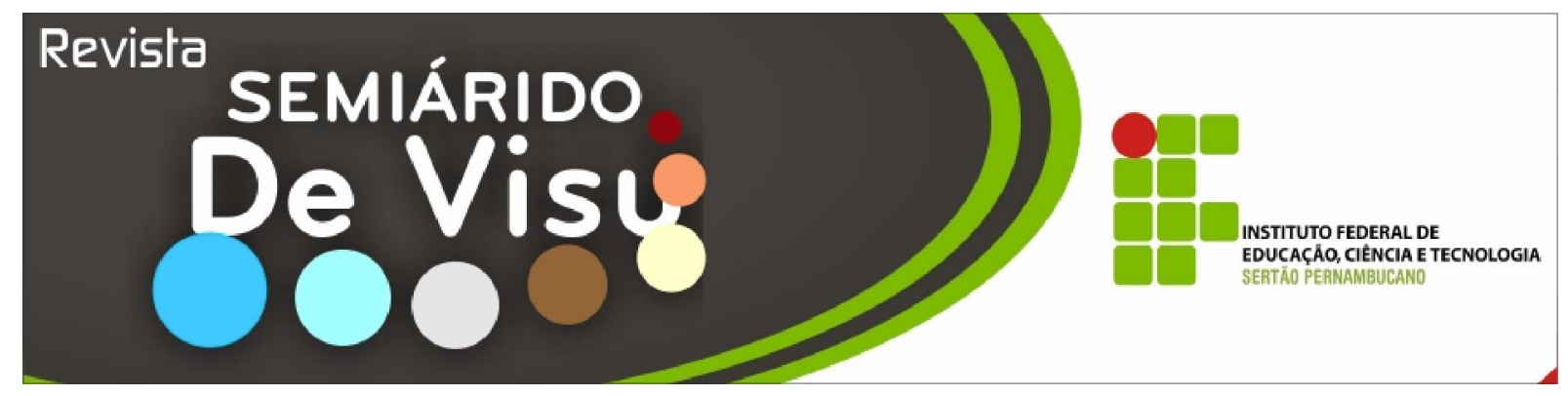

\title{
Análise sensorial de ovos de codorna submetidos a diferentes processos de conservação
}

\author{
Marcelo Iran de Souza Coelho ${ }^{1}$, Vanicléia Oliveira da Silva ${ }^{2}$, Maria Cláudia Soares Cruz \\ Coelho ${ }^{1}$, Marcos dos Santos Lima ${ }^{1}$, Valéria Souza Santos ${ }^{2}$. \\ ${ }^{1}$ Professores do IF SERTÃO-PE, ${ }^{2}$ Tecnólogas em alimentos IF Sertão-PE, e-mail: marcelo.iran@ifsertao-pe.edu.br
}

RESUMO: Objetivou-se verificar a aceitação de ovos de codorna, em conserva (T1), defumados (T2) e cozidos (T3), através de análises sensorial, estatística descritiva e multivariada. Para aceitação do produto, utilizou-se escala estruturada de nove pontos, já para atitude de compra foi de 5 pontos. Observou-se para aparência melhor aceitabilidade das amostras T1 e pior das amostras T2. A intensidade de cor no tratamento com defumação conferiu uma coloração próxima ao ideal. Com relação ao aroma, verificou-se que os tratamentos T1 e T2, desagradaram ligeiramente. $\mathrm{Na}$ textura e de modo geral o T3 agradou moderadamente, enquanto T1 e T2 desagradaram ligeiramente e nem agradaram/nem desagradaram, respectivamente. Com relação ao sabor, 21\% dos degustadores declararam que a intensidade de sabor estava extremamente mais forte nas amostras T2 e que as amostras T3 apresentaram sabor ideal. Verificou-se que 55\% dos consumidores declararam que não compraria T1, que 43\% certamente não compraria T2 e, que T3 seria adquirido por 49\% dos degustadores. Observou-se na MANOVA efeito significativo entre os tratamentos e correlação moderada entre aroma e modo geral. Na análise de componentes principais (ACP) observou-se variabilidade nas respostas dos degustadores. Concluindo-se que para o uso dos processos tecnológicos de conserva e defumação em ovos de codorna, faz-se necessário aperfeiçoamento no preparo e, que a MANOVA e a ACP foram determinantes na identificação das correlações e variações existentes entre os tratamentos e as variáveis.

Palavras-chave: conserva, defumação, cocção, análise de componentes principais.

\section{Sensory analysis of quail eggs submitted to different processing conservation}

Abstract: This study assessed the acceptance of quail eggs, pickled (T1), smoked (T2) and cooked (T3) through sensory analysis, descriptive statistics and multivariate analysis. For acceptance of the product, we used structured nine-point scale, as for attitude purchase was 5 points. Was observed to look better acceptability of the samples T1 and T2 samples the worst. The intensity of color in dealing with smoking conferred a color close to ideal. Regarding the smell, it was found that T1 and T2, slightly displeased. In texture and generally moderately pleased $\mathrm{T} 3$, while $\mathrm{T} 1$ and $\mathrm{T} 2$ pleased or displeased slightly and / or displeased, respectively. With respect to taste, $21 \%$ of the tasters declared that the intensity of flavor was very strong in samples T2 and T3 samples showed that the optimal flavor. It was found that $55 \%$ of consumers said they would not buy $\mathrm{T} 1$, which certainly would not buy $43 \% \mathrm{~T} 2$, and $\mathrm{T} 3$ that would be acquired for $49 \%$ of tasters. We observed in the MANOVA significant effect between treatments and aroma and moderate correlation between overall. In principal component analysis (PCA) revealed variability in the responses of the panelists. It was concluded that for the use of technological processes of canning and smoking in quail eggs, it is necessary in the preparation and improvement, the ACP and MANOVA were instrumental in the identification of correlations and variances between the treatments and variables.

Keywords: canning, smoking, cooking, principal component analysis 
Marcelo Iran de Souza Coelho et al.

\section{Introdução}

$\mathrm{O}$ vo de codorna, além de ser excelente fonte de vitaminas, minerais e proteínas, vem apresentando aumento significativo no seu consumo (Seibel et al., 2010). Este produto possui em sua composição $6,5 \mathrm{mg}$ de proteína, $40 \mathrm{mg}$ de vitamina, $112 \mathrm{mg}$ de fósforo, $1,85 \mathrm{mg}$ de ferro e $31 \mathrm{mg}$ de cálcio em $50 \mathrm{~g}$, constituindo-se em excelente fonte de nutrientes (Redder, 2005).

No entanto, para atender o mercado que está cada vez mais exigente, é preciso inovar com produtos práticos, saudáveis e que agradem ao gosto do consumidor. Então, podese associar a rica fonte de nutrientes contidos nos ovos de codorna com processos tecnológicos que propiciam maior vida útil e melhora nas características físico-químicas e organolépticas. Por isso, a estes produtos, podem ser aplicados os processos conserva, defumação e cocção.

A conserva aumenta o tempo de vida útil através da alteração do $\mathrm{pH}$, devido aos ácidos orgânicos presentes, inibindo o crescimento microbiano, além de conferir praticidade para o consumidor, por estar pronto para servir. Luck e Jager (1997) demonstraram que a ação antimicrobiana dos conservantes (como o ácido acético e o sal) baseia-se em efeitos sobre um ou mais dos seguintes componentes/atividades: DNA, membrana plasmática, parede celular, síntese protéica, atividade enzimática, transporte de nutrientes.

Azeredo (2004) relatou que o uso de calor utilizado no processo de defumação para conservar alimentos tem por objetivo a redução da carga microbiana e a desnaturação de enzimas, desta forma, apesar de que defumar ovos não seja uma prática comum, quando bem aplicada, pode propiciar maior vida útil, através da diminuição da atividade de água e do aquecimento que destrói a flora microbiana presente na superfície do alimento, ocorrendo também mudanças significativas nas suas características organolépticas, principalmente na cor e sabor, que se tornam mais acentuados de acordo com o processo que for empregado.

Com relação ao interesse pela cocção de ovos, este é estabelecido porque previne salmonelose e melhora a digestibilidade da proteína por meio da coagulação, aumentando a biodisponibilidade do ferro da gema, pela inativação de enzimas.

Outro ponto que deve ser abordado refere-se ao objetivo final de todo trabalho realizado nas áreas de desenvolvimento de produtos, que consisti no consumidor e na sua avaliação que vai estar embasada na aceitabilidade e evidentemente nos custos dos produtos. Não seria viável produzir alimentos que não fossem de agrado do consumidor, por isto a importância da realização de análises sensoriais.

A análise sensorial é usada para evocar, medir, analisar e interpretar as reações às características dos alimentos e materiais como são percebidas pelos sentidos da visão, olfato, gosto, tato e audição (ABNT, 1993). Ferreira et al, (2000a) afirmaram que o homem tem habilidade natural para comparar, diferenciar e quantificar os atributos sensoriais, neste contexto, a análise sensorial utiliza-se dessa habilidade para avaliar alimentos e bebidas, empregando a metodologia apropriada aos objetivos do estudo e o tratamento estatístico dos dados obtidos.

Não há referência sobre o processamento em escala industrial de ovos de codorna no Brasil, por outro lado, a literatura sobre o perfil sensorial deste tipo de produto é escassa, neste caso, o estabelecimento do perfil sensorial de ovos de codorna submetidos a processamentos de conserva, defumação e cocção, que servirá como referência para a padronização no processamento deste produto, sendo de extrema importância estudar processos tecnológicos que possam ser aplicados a esta matéria prima, para poder inovar e satisfazer o consumidor cada vez mais exigente. 
Marcelo Iran de Souza Coelho et al.

Com isto, o presente trabalho tem como objetivo verificar a aceitação de três amostras de ovos de codorna, em conserva, defumados e cozidos, através de análise sensorial e análises estatísticas MANOVA e Análise de componentes principais, para sugerir variáveis mais importantes.

\section{Material e métodos}

A presente pesquisa foi realizada nas instalações do setor de Agroindústria do IF SETÃO-PE, Campus Petrolina Zona Rural, onde os ovos foram processados e avaliados sensorialmente no Laboratório de Instrumentação de Alimentos do Campus Petrolina.

Utilizou-se 300 ovos de codorna, que foram divididos em três grupos de 100 unidades, cada grupo foi submetido a três tratamentos (T1 - conserva, T2 - defumação e T3 - cocção) com 3 repetições. Após cozinhar as amostras durante sete minutos e descascar foram separadas em três partes. A primeira parte foi acondicionada em vidros herméticos esterilizados, onde continham uma solução de $500 \mathrm{~mL}$ de ácido acético e $40 \mathrm{~g}$ de cloreto de sódio. Outra parte das amostras foi defumada durante uma hora, com temperatura de defumação entre $60^{\circ}$ a $80^{\circ} \mathrm{C}$. A terceira parte dos ovos de codorna foi acondicionada em vidros herméticos esterilizados e, armazenada em câmara de refrigeração até a realização da análise sensorial.

As avaliações sensoriais foram realizadas de acordo com o método citado em Moraes (1985), em cabines individuais, longe de ruídos e odores, em horários previamente estabelecidos, excluindo uma hora antes e duas horas após o almoço. A composição do painel de provadores constituiu-se de 100 pessoas escolhidas aleatoriamente, de ambos os sexos, de diferentes faixas etárias e não treinadas, entre eles professores, funcionários $\mathrm{e}$ estudantes do IF SERTÃO-PE. As amostras foram servidas em bandejas plásticas descartáveis, codificadas com letras, acompanhadas de biscoito água e sal e água mineral à temperatura ambiente, para remoção do sabor residual entre as amostras, onde foram apresentadas simultaneamente aos provadores, com a orientação de provarem um por vez, da esquerda para a direita, juntamente com o questionário. Analisaram-se os quesitos aparência, sabor, cor, aroma, textura e o produto de maneira geral.

A aceitabilidade dos ovos de codorna foi determinada com a participação de consumidores potenciais do produto, utilizando-se uma Escala Hedônica Estruturada de nove pontos (9- gostei extremamente; 8gostei muito; 7- gostei moderadamente; 6gostei ligeiramente; 5- nem gostei/nem desgostei; 4- desgostei ligeiramente; 3desgostei moderadamente; 2- desgostei muito; 1- desgostei extremamente), conforme citado em Silva (1997), para os atributos aparência, intensidade da cor, o produto de um modo geral, aroma e textura. Avaliou-se também o grau de intensidade de sabor e intenção de compra.

Foi realizada análise estatística descritiva e multivariada, com análises de correlação entre as amostras em conserva, defumadas e cozidas e as variáveis aparência, intensidade de cor, aroma, textura e avaliação geral, além de análise de componentes principais, utilizando-se o programa estatístico SAS System for Windows 9.0.

\section{Resultados e discussão}

Aparência é o fator de qualidade de maior importância do ponto de vista da comercialização, podendo ser avaliada por diferentes atributos tais como grau de frescor, tamanho, forma, cor, higiene, maturidade e ausência de defeitos (Chitarra, 1998). De acordo com as análises realizadas constatou-se que (figura 1) para a variável aparência ocorreu 
melhor aceitabilidade das amostras $\mathrm{T} 1$ e pior das amostras $\mathrm{T} 2$, provavelmente a cor e $\mathrm{o}$ brilho das amostras foram atributos óbvios de julgamento desta variável.

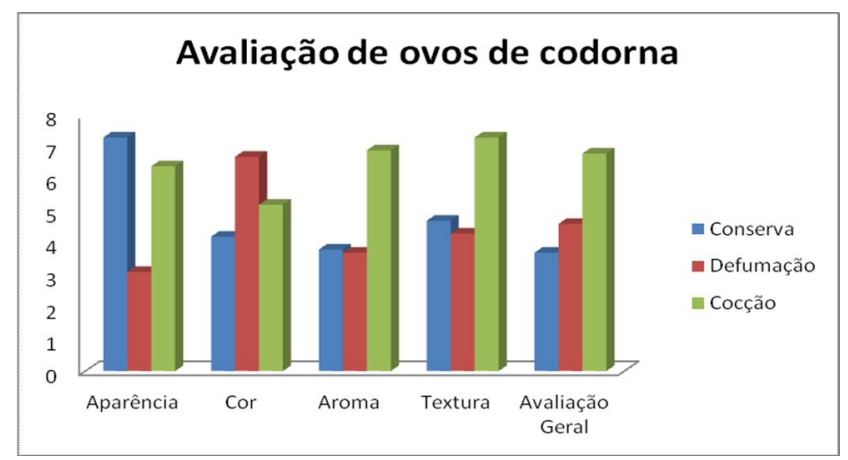

Figura 1 - Preferência dos degustadores.

Para o quesito intensidade de cor, o tratamento com defumação conferiu uma coloração próxima ao ideal, que possivelmente foi favorecida pela coloração característica destes produtos.

Com relação ao aroma foi observado que os tratamentos T1 e T2 desagradaram ligeiramente os degustadores, este fato pode ser devido ao odor do ácido acético e da fumaça, processos inerentes aos tratamentos testados, onde, segundo Chaves e Stroesser (1996) o aroma, numa perspectiva fisiológica, é a sensação que se percebe por meio das células receptoras olfativas, quando estimuladas por substâncias voláteis que passam pela boca.

Já a textura apresentou resultados semelhantes ao aroma, notando-se que o T3 agradou moderadamente, $\mathrm{T} 1$ e $\mathrm{T} 2$ desagradaram ligeiramente, demonstrando que o processo de defumação e conserva levou a uma alteração na textura dos ovos de codorna, influenciando os atributos sensoriais deste tratamento.

De um modo geral pode-se dizer que os participantes concluíram que T3 agradou moderadamente, enquanto T1 e $\mathrm{T} 2$ desagradaram ligeiramente $\mathrm{e}$ nem agradaram/nem desagradaram, respectivamente.

A intensidade de sabor foi sentida extremamente mais forte em $\mathrm{T} 1$, verificando que T2 apresentou intensidade ideal de sabor. De acordo com Bobbio e Bobbio (1992), os sabores básicos são quatro: azedo, doce, salgado e amargo e estes não são específicos de um alimento particular. Os quatro sabores estão ligados à existência, no alimento, de um ou vários compostos cuja estreoquímica, estrutura e composição é atribuída à propriedade de produzir, nas mucosas da boca, um ou mais dos sabores básicos por sua ligação com grupos receptores da proteína da mucosa bucal (Ferreira et al., 2000b)

A figura 2 demonstra a aceitação da intensidade de sabor dos tratamentos, onde, verifica-se que $43 \%$ dos avaliadores relataram que o sabor dos ovos em conserva está extremamente mais forte do que o ideal, contudo, $0 \%$ considerou a amostra extremamente mais fraca que o ideal. 
Marcelo Iran de Souza Coelho et al.

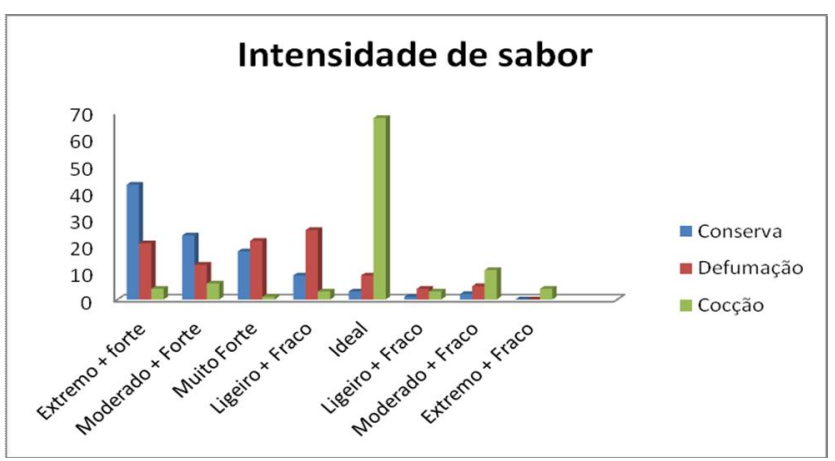

Figura 2 - Avaliação da intensidade do sabor de ovos de codorna em conserva, defumados e cozidos.

Com relação às amostras defumadas (T2) apenas $21 \%$ dos degustadores declararam que a intensidade de sabor das amostras está extremamente mais forte que o ideal e $26 \%$ declararam que a amostra está ligeiramente mais forte que o ideal (figura 2). Identifica-se ainda na figura 2, concernente com $\mathrm{o}$ tratamento T3, que para a maioria dos degustadores o sabor ideal foi dos ovos cozidoss, provavelmente devido ao fato das outras amostras estarem com odor e sabor pouco mais forte que o ideal.

Para a variável intenção de compra, verificou-se, conforme figura 3 , que boa parte dos avaliadores não compraria estes produtos. Destes, 55\% declararam que não compraria os ovos em conserva e $43 \%$ certamente não compraria os ovos defumados. Considerado os ovos cozidos o melhor tratamento, na intenção de compra, seria adquirido por $49 \%$ dos degustadores.

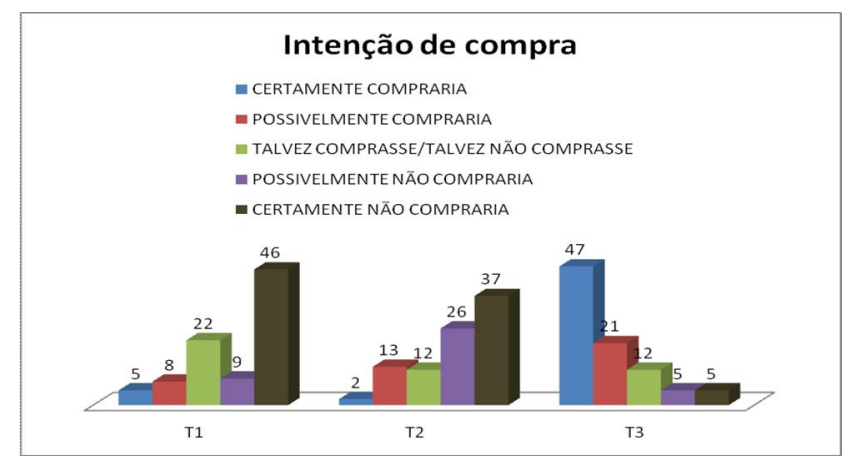

Figura 3 - Avaliação da intenção de compra de ovos de codorna em conserva, defumados e cozidos.

Pereira et al. (1996), analisaram ovos de codorna em conserva e verificaram que os testes sensoriais indicaram que a formulação com ácido lático e $1,5 \%$ de sal apresentou maior aceitabilidade. Já Berbari et al. (1998), estudaram a conservação de ovos de codorna com diferentes tipos de ácido: cítrico, fosfórico ou ácido cítrico junto com vinagre e, mostraram que a adição de ácido e conservador evitou a deterioração microbiológica do produto, mas a adição da mistura de ácido cítrico e vinagre prejudicaram o gosto dos ovos, tornando-os inaceitáveis para consumo.

De acordo com a MANOVA e o teste de Wilks' Lambda, observou-se estatisticamente efeito dos tratamentos sobre as variáveis estudadas a nível de $1 \%$ de probabilidade, verificando-se ainda o efeito das 
Marcelo Iran de Souza Coelho et al.

correlações entre as variáveis e procedendo posteriormente a análise de componentes principais por tratamento.

A fim de se quantificar as correlações foram calculados os coeficientes de correlação linear. Segundo Shimakura e Ribeiro Júnior (2005), quando o coeficiente de correlação linear (r) entre duas variáveis é, em módulo, menor que 0,199 , considera-se que houve uma correlação muito fraca. Quando o coeficiente de correlação linear, em módulo, estiver entre 0,20 e 0,39 , a correlação é considerada fraca, entre 0,40 e 0,69 , a correlação é considerada moderada, entre 0,69 e 0,89 , a correlação é considerada forte e superior a 0,90 , a correlação é considerada muito forte.

Conforme as classificações descritas quanto aos coeficientes de correlação, verificou-se (tabela 1) moderada correlação entre aroma e modo geral, sendo esta correlação positiva e significativa a $1 \%$ de probabilidade. Destaca-se fraca correlação entre aroma e textura, aroma e aparência, textura e modo geral (positivamente) e aparência e intensidade de cor (negativamente). As demais variáveis apresentaram correlações muito fracas.

Tabela 1 - Correlação lineares para os parâmetros sensoriais avaliados nos ovos de codorna

\begin{tabular}{lccccc}
\hline & Aparência & Intensidade cor & Modo geral & Aroma & Textura \\
Aparência & 1,000 & $-0,2591$ & 0,1557 & 0,2998 & 0,1422 \\
Intensidade de cor & $-0,2591$ & 1,000 & 0,0954 & 0,0105 & $-0,1094$ \\
Modo geral & 0,1557 & 0,0954 & 1,000 & 0,6829 & 0,2711 \\
Aroma & 0,2998 & 0,0105 & 0,6829 & 1,000 & 0,3858 \\
Textura & 0,1422 & $-0,1094$ & 0,2711 & 0,3858 & 1,00 \\
\hline
\end{tabular}

A partir das tabulações e do tratamento estatístico foi realizada uma Análise de Componentes Principais (ACP), de acordo com Faria e Yotsuyanagi (2002), entre as médias das notas dos provadores por atributo sensorial para os ovos de codorna em conserva, defumados e cozidos, onde se observou a variabilidade nas respostas dos degustadores (figura 4).

Segundo Muñoz et al (1992), em uma figura que represente a $\mathrm{ACP}$, vetores com medidas mais distantes de zero, correspondem a variações com maior influência sobre o valor do Componente Principal, enquanto que, vetores mais próximos de zero, indicam que correspondem a uma variável com pequena influência sobre o Componente Principal. Portanto, é possível verificar que todos os atributos gerados para as amostras de ovos de codorna, correspondem a variações com grande influência. 


\section{Marcelo Iran de Souza Coelho et al.}

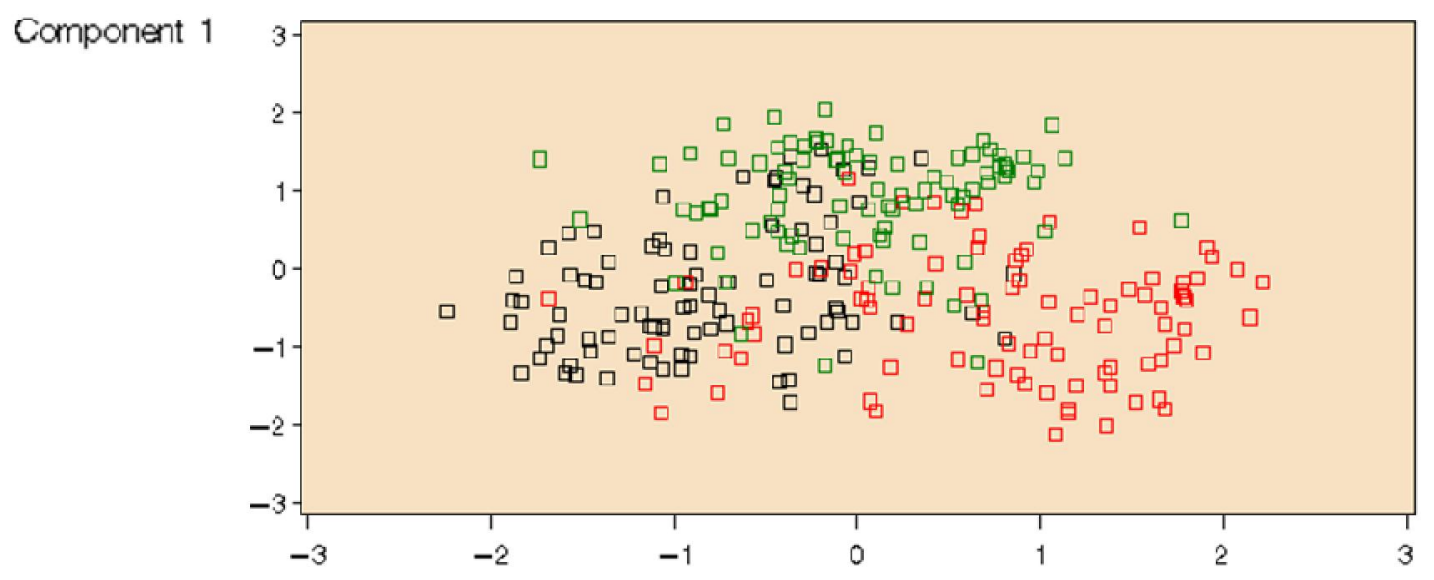

Component 2

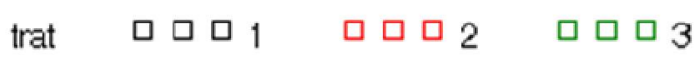

Figura 4 - Análise de Componentes Principais (ACP) entre médias de notas dos provadores por atributo sensorial para ovos de codornas em conserva, defumados e cozidos.

Devido à diferença estatística apresentada na análise de MANOVA, foi gerada uma análise de componente principal para cada tratamento, onde observou-se que para T1 (tabela 3) os três primeiros componentes explicaram juntos, $82 \%$ da variação ocorrida entre as amostras de ovos de codorna em conserva, sendo os atributos modo geral e aroma (positivamente) que contribuíram com maior peso sobre variabilidade associada ao primeiro componente. Com relação ao componente 2, aparência (negativamente) e textura (positivamente) foram os que mais contribuíram.

Com relação ao tratamento 2 , observouse na tabela 4 que os três primeiros componentes explicaram juntos, $77 \%$ da variação ocorrida entre as amostras de ovos de codorna defumados, sendo os atributos modo geral e aroma (positivamente) que contribuíram com maior peso sobre variabilidade associada ao primeiro componente, seguindo a mesma resposta do tratamento 1 , já com relação ao componente 2 , as variáveis intensidade de cor foi a que mais contribuiu com variação. 
Marcelo Iran de Souza Coelho et al.

Tabela 3 - Autovetores calculados para as amostras de ovos de codorna em conserva

\begin{tabular}{lccccc}
\hline Parâmetros analisados & Comp 1 & Comp 2 & Comp 3 & Comp 4 & Comp 5 \\
Aparência & 0,124121 & $-0,638371$ & 0,421439 & 0,631551 & 0,024692 \\
Intensidade de cor & 0,039047 & 0,418005 & 0,872645 & $-0,174451$ & 0,178336 \\
Modo geral & 0,671056 & $-0,140746$ & $-0,143324$ & $-0,205234$ & 0,683529 \\
Aroma & 0,689900 & 0,010217 & 0,078111 & $-0,149868$ & $-0,703827$ \\
Textura & 0,238310 & 0,630746 & $-0,185029$ & 0,711428 & 0,070729 \\
Acumulado (\%) & 37 & 62 & 82 & 96 & 100 \\
\hline
\end{tabular}

Tabela 4 - Autovetores calculados para as amostras de ovos de codorna defumados

\begin{tabular}{|c|c|c|c|c|c|}
\hline Parâmetros analisados & Comp 1 & Comp 2 & Comp 3 & Comp 4 & Comp 5 \\
\hline Aparência & 0,480368 & $-0,109569$ & 0,728387 & $-0,347236$ & $-0,325760$ \\
\hline Intensidade de cor & 0,075933 & 0,701975 & 0,424760 & 0,381701 & 0,418746 \\
\hline Modo geral & 0,574503 & 0,230791 & $-0,366478$ & 0,449725 & $-0,529266$ \\
\hline Aroma & 0,612352 & 0,044274 & $-0,350628$ & $-0,429455$ & 0,561866 \\
\hline Textura & 0,241768 & $-0,663326$ & 0,178282 & 0,589107 & 0,350308 \\
\hline Acumulado (\%) & 33 & 59 & 77 & 91 & 100 \\
\hline \multicolumn{6}{|c|}{$\begin{array}{l}\text { No que concerne ao tratamento com } \\
\text { ovos cozidos (tabela 5), foi constatado que as }\end{array} \begin{array}{l}\text { proporcionando } \\
\text { componente } 1 .\end{array}$} \\
\hline Parâmetros analisados & Comp 1 & Comp 2 & Comp 3 & Comp 4 & Comp 5 \\
\hline Aparência & 0,545362 & 0,009964 & 0,104967 & $-0,812996$ & 0,174645 \\
\hline Intensidade de cor & 0,200044 & 0,556857 & $-0,805339$ & 0,034723 & $-0,010770$ \\
\hline Modo geral & 0,567558 & $-0,130600$ & 0,064831 & 0,520841 & 0,620760 \\
\hline Aroma & 0,573321 & 0,079812 & 0,218494 & 0,254081 & $-0,743395$ \\
\hline Textura & $-0,108369$ & 0,816324 & 0,537092 & 0,044722 & 0,177209 \\
\hline Acumulado (\%) & 40 & 61 & 79 & 90 & 100 \\
\hline
\end{tabular}


Marcelo Iran de Souza Coelho et al.

\section{Conclusões}

Podem-se utilizar os processos tecnológicos de conserva, defumação e cocção em ovos de codorna, no entanto, as amostras em conserva e defumadas não foram capazes de agradar satisfatoriamente aos consumidores nas condições da presente pesquisa. Sendo, portanto, necessário aperfeiçoamento nos processos de preparo, como o uso de condimentos, e realização de novos testes sensoriais.

A análise multivariada (MANOVA) e de Componentes Principais foram determinantes na identificação das correlações e variações existentes entre os tratamentos e as variáveis.

\section{Referências}

ASSOCIAÇÃO BRASILEIRA DE NORMAS TÉCNICAS. Teste triangular em análise sensorial dos alimentos e bebidas - NBR 12995. São Paulo: ABNT, 1993.

\section{AZEREDO, HENRIETTE MONTEIRO CORDEIRO DE. Fundamentos de estabilidade de alimentos. Fortaleza: Embrapa Agroindústria Tropical, 2004. 195 p.}

BERBARI, S.A.G.; PASCHOALINO, J.E.; SILVEIRA, N.F.A.; NISIDA, A.L.A.C. Conservação de Ovos de Codorna por Métodos Combinados. XVI Congresso Brasileiro de Ciência e Tecnologia de Alimentos. Rio de Janeiro: SBCTA, 1998, trabalho $\mathrm{n}^{\circ} 267$.

BOBBIO, P.A.; BOBBIO, F.O. Química do processamento de alimentos. $2^{\mathrm{a}}$ ed. São Paulo: Varela, 1992, p.121-122.

CHAVES, J.B.P.; SPROESSER, R.L. Práticas de laboratório de análise sensorial de alimentos e bebidas. Viçosa: Imprensa Universitária, 1996, 81p.
CHITARRA, M.I.F. Colheita e qualidade de produtos vegetais. BOREM, F.M.; CHITARRA, A.B. Armazenamento e Processamento de Produtos Agrícolas. Poços de Calda: UFLA/SBEA, 1998. Cap.1, p.1-58.

FARIA, E. V. de YOTSUYANAGI, K. Técnicas de análise sensorial. Campinas, SP: LAFISE/ITAL, 2002. 116 p.

FERREIRA, V. L. P.; ALMEIDA, T. C. A.; PETTINELli, M. L. C. V.; SILVA, M. A. A. P.; CHAVES, J. B. P.; BARBOSA, E. M. M. Análise sensorial: testes discriminativos e afetivos. Campinas. SBCTA, 2000a. 127p.

FERREIRA, J. C.; MATA, M. E. R. M. C.; BRAGA, M. E. D. Análise sensorial da polpa de umbu submetida a congelamento Inicial em temperaturas criogênicas e armazenadas em Câmaras frigoríficas. Revista Brasileira de Produtos Agroindustriais, v. 2, n. 1, p. 7-17, 2000b.

LUCK, E.; JAGER, M. Antimicrobial food additives: characteristics, uses, effects. 2 nd.ed. Berlin: Springer-Verlag, 1997.260 p.

MORAES, M. A. C. Métodos de avaliação sensorial dos alimentos. Campinas: Unicamp/FEA, 1985, 85p.

MUÑOZ, A.M., CIVILlE,G.V., CARR,B.T. Sensory evaluation in quality control. New York: Van Nostrand Reinhold, 1992. 240 p.

PEREIRA，A.J.G.; LABOISSIÈRE， L.H.E.; NOLASCO, V.M.; CALDAS, R.A. Fabricação de Ovos de codorna em Conserva. Resumo In: XV Congresso Brasileiro de Ciência e Tecnologia de Alimento. Poços de Calda: SBCTA, 1996 p. 03

REDDER, E. Compare o ovo de codorna com o de galinha. Revista Saúde é vital. São Paulo, p.27, abr.2005.

STATISTICAL ANALYSES SYSTEM - SAS. SAS'S user's guide. SAS for windows. Washington: 1997. 46p. 
Marcelo Iran de Souza Coelho et al.

SEIBEL, N. F.; SCHOFFEN, D. B.; SHIMAKURA, S. E.; RIBEIRO JUNIOR, P. J. QUEIROZ, M. I.; SOUZA-SOARES, L. A. de. Estatística. 2005. Disponível em: Caracterização sensorial de ovos de codornas http://www.est.ufpr.br/ paulojus/CE003/ce003/ alimentadas com dietas modificadas. Revista . Acesso em: 5 dez. 2006.

de Ciência e Tecnologia de Alimentos, v.30, SILVA, M. A. A. P. Métodos de avaliação n.4, p.884-889, 2010. sensorial de alimentos. Curso de extensão, Unicamp, Campinas, 71p. 1997 (apostila). 